\title{
3D INTEGRATED METHODOLOGIES FOR THE DOCUMENTATION AND THE VIRTUAL RECONSTRUCTION OF AN ARCHAEOLOGICAL SITE
}

\author{
C. Balletti *, F. Guerra, V. Scocca, C. Gottardi \\ Università Iuav di Venezia, S. Croce 191, 30135 Venezia, Italia - (balletti, guerra, vscocca, cgottardi)@iuav.it
}

Commission V, WG V/4

KEY WORDS: Archaeological Site, Documentation, Laser Scanning, Photogrammetry, 3D Modelling, 3D Reconstruction

\begin{abstract}
:
Highly accurate documentation and 3D reconstructions are fundamental for analyses and further interpretations in archaeology. In the last years the integrated digital survey (ground-based survey methods and UAV photogrammetry) has confirmed its main role in the documentation and comprehension of excavation contexts, thanks to instrumental and methodological development concerning the on site data acquisition.

The specific aim of the project, reported in this paper and realized by the Laboratory of Photogrammetry of the IUAV University of Venice, is to check different acquisition systems and their effectiveness test, considering each methodology individually or integrated.

This research focuses on the awareness that the integration of different survey's methodologies can as a matter of fact increase the representative efficacy of the final representations; these are based on a wider and verified set of georeferenced metric data. Particularly the methods' integration allows reducing or neutralizing issues related to composite and complex objects' survey, since the most appropriate tools and techniques can be chosen considering the characteristics of each part of an archaeological site (i.e. urban structures, architectural monuments, small findings).

This paper describes the experience in several sites of the municipality of Sepino (Molise, Italy), where the 3d digital acquisition of cities and structure of monuments, sometimes hard to reach, was realized using active and passive techniques (rage-based and image based methods).

This acquisition was planned in order to obtain not only the basic support for interpretation analysis, but also to achieve models of the actual state of conservation of the site on which some reconstructive hypotheses can be based on.

Laser scanning data were merged with Structure from Motion techniques' clouds into the same reference system, given by a topographical and GPS survey.

These $3 \mathrm{~d}$ models are not only the final results of the metric survey, but also the starting point for the whole reconstruction of the city and its urban context, from the research point of view. This reconstruction process will concern even some areas that have not yet been excavated, where the application of procedural modelling can offer an important support to the reconstructive hypothesis.
\end{abstract}

\section{INTRODUCTION}

Today's technologies and methodologies in archaeology documentation allow to record the position, size and shape, as well as generate very accurate and realistic 3D models both in terms of geometry and textures, that are required in any project related to the conservation of $\mathrm{CH}$, forming an important element of the documentation and analysis process (Patias et al., 2006; English Heritage, 2011).

The methods and tools used in the survey of archaeological sites cover a wide range according to the characteristics of the site and of the required precisions considering the different scale of representation. The survey becomes a very complex operation both from the methodological and operational point of view. It requires critical interpretation abilities for a correct comprehension of the surveyed object from which the correct strategies can be derived to obtain the best result from the survey operations (Guidi et al. 2004; Cignoni et al., 2008; Remondino et al., 2010; Brunetaud et al., 2012; Chiabrando et al., 2014; Balletti et al., 2014).

Several scenarios could appear, each one requiring an adequate planning to obtain the best results from the survey operations. Particularly, the actual spectrum of methodologies and instruments is extremely wide: it goes from the direct survey, a simpler but fine and useful method, to the more sophisticated known as indirect measurement. Often, the multi-resolution approach and the application of different techniques and methodologies (such as photogrammetry, laser scanning, topographic survey, etc.) provide better results in terms of accuracy and optimisation of the final product (2D or 3D).

\section{THE STUDY CASE}

The archaeological investigations that have been conducted on several occasions in the area of Sepino since 1820 and that are still in progress, have outlined a strong topographical fragmentation of the cantonal settlements and, especially in recent decades, have focused on the shaping of their respective and articulated forms of integration. The structural evidence of Altilia (and later the municipal urban plant of Saepinum), the fortified settlement of Terravecchia and the sanctuary of San Pietro di Cantoni have always been considered the keystones of a sophisticated occupation, extended and stable in the only apparent contradiction between small settlement with the function of magnetizer and temporary centre of gravity, and sprawling and scattered settlement.

The easy and transparent identification of Terravecchia (Fig. 1a), at a height of $953 \mathrm{~m}$ above sea level, with the ancient city of

\footnotetext{
* Corresponding author. This is useful to know for communication with the appropriate person in cases with more than one author.
} 
Saepinum, at the centre of important events during the third Samnite war, has always raised curiosity, suggested and urged cognitive interventions through surveying, recognition and excavation actions (Colonna, 1962; Scerrato, 1981). However, the difficulties of carrying out the interventions due to the steep slopes, the absence of useful connections, the spontaneous reforestation and in short, due to the marginality of the place, have not allowed an extensive, detailed and systematic exploration until recent years.

The sanctuary of San Pietro di Cantoni (Fig. 1b) is located along the north-eastern side of the Matese, at a low hill (altitude $666 \mathrm{~m}$ above sea level), and is configured as a point of balance and also as a topographical point, between high areas used for defence and valley areas destined to the trade and the production within the community and the canton of Saepinates.
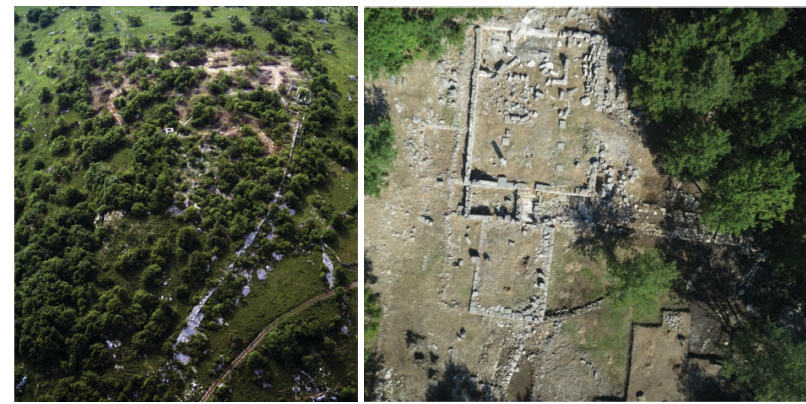

Figure 1. Terravecchia (a) and San Pietro di Cantoni (b)

The complex is located on a large artificial terrace, with a polygonal wall inside of which there are the remains of an Italic monumental temple (prostyle tetrastyle in antis), built around the middle of the second century B.C. (Matteini Chiari, 2004) and accessible by means of a paved structure culminating in a staircase located along the North-eastern angle of the podium and orthogonal to it.

Saepinum (Fig. 2), the city of the plain (altitude 553m above sea level), is born, as suggested by the same name, from the root of the verb saepio ("fence"), as a place to store and park the transhumant flocks along the tratturo Pescasseroli Candela. Enclosed in a quadrangular area of about 12 acres from the city walls, made in opus quasi reticulatum and with a total length of $1,270 \mathrm{~m}$., is, according to what is documented by the investigations of the excavation performed several times within the city limits, largely vital and functionally organized since the second century. B.C. as it was a small proto-urban community centre. However, the city lives its period of maximum building fervour and consistent urban definition only during the Augustan age, a few decades after the bestowal of the municipal statute within the Regio IV augustea (Matteini Chiari et al., 1993).

\section{THE SURVEY CAMPAIGN}

A first survey campaign, which involved the use of topographic instruments and terrestrial laser scanners and of a multi-rotors hexacopter for the acquisition of aerial photogrammetric photos took place in July 2013 in the archaeological site of Terravecchia di Sepino. The intervention, characterized by absolutely positive outcomes despite the difficulties dictated by the limited accessibility of the place, covered three different areas of the excavations: the church of San Martino, located behind the Northern slopes of the settlement, the so-called rectangular tower, located in the vicinity of the acropolis, and a long stretch of walls between the Porta Medievale, one of road access to the medieval village, and Postierla del Matese, a covered pedestrian gate inside the mighty samnitic walls in cyclopean masonry with double curtain. Unlike the laser scanning instrumentation, used with positive results in all areas of the programmed intervention, it was not possible to use the drone in the area occupied by the church of San Martino because of the extremely low hedges of trees that reduced the room for manoeuvre of the drone itself and therefore made the flight operations unsafe. The creation of an adequate aerial photo coverage, to ensure the integration of ground-acquired data, made of nadiral and oblique photogrammetric photos taken in succession, was assured by the use of the drone in the area of the rectangular tower and in between the Porta Medievale and Postierla del Matese by taking five subsequent flight sessions.

For the topographic support of the scans and photogrammetric photos, both aerial and ground-based, we did a special survey, simultaneously and in parallel with the scanning sessions, using for this purpose 14 topographical network stations, used for the entirety of the excavation operations, constructed from a pair of cemented cornerstones, georeferenced with GPS instrumentation in a planimetric and altimetric (global type) reference system, and adopting a flat -coordinate system GaussBoaga, functional to georeference all excavation data on cartographic support CTR at 1: 5000 .

The use of the same acquisition techniques has also marked the survey campaign, carried out in the summer of 2013 and 2014, in the area of San Pietro di Cantoni: here we carried out simultaneously ten scans with laser scanner and five different flying sessions with the drone with the aim of achieving a detailed photographic documentation of the main structures in the sanctuary.

In this case the almost complete absence of trees allowed to achieve an almost complete photographic documentation of the sacred area through the acquisition of aerial, nadiral and oblique images, through sequences of contiguous strips. The simultaneous survey with GPS instrumentation also allowed to place laser scanning, aerial photogrammetric and terrestrial surveys in a unique reference system.

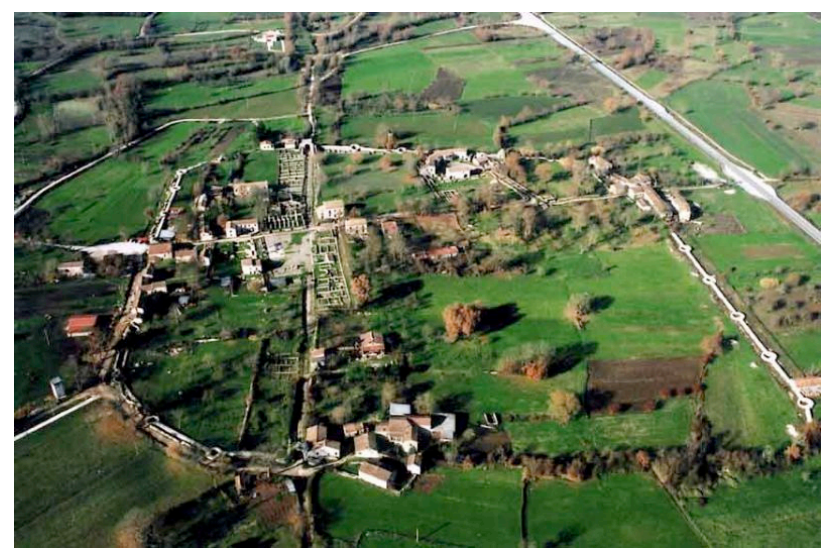

Figure 2. The archaeological site of Saepinum.

A similar survey campaign, carried out once again together with the Superintendence for Archaeological Heritage of Molise (Soprintendenza per i Beni Archeologici del Molise) and with the University of Perugia- Urban Planning and Surveying, in the first edition of the Summer School of Surveying and 3D Modeling, held in Sepino between the 20te and 30th July 2014, has affected a large portion of urban and extra-urban areas of the Roman town of Saepinum. The aim is to provide a 3D model of the entire urban plan that represents the actual condition and that suggests a documented and possible reconstruction in its various stages of life. The result of this work, started for cognitive and informative reasons, aims at the 
preparation of future digital papers fully accessible to the visitors of the archaeological site and aimed at facilitating the reading and understanding of the structures autonomously with the aid of mass mobile devices. For this reason we have undertaken the survey of the major urban infrastructures, which is to say the forensic area, the theatre, the commercial and residential buildings alongside the decumanus as well as the layout of the two main urban roads (Cardo and Decumanus Maximi).

The surveying activities were carried out also in two of the four main gates of the town, Porta Boiano and Porta Benevento, and also just outside the city walls on two tombs which are the ara mausoleum of Publius Numisius Ligus, the tholobate mausoleum of Caius Ennius Marsus and also the blocks of grade plans of the base plinth of a third ara funerary monument which was discovered during the excavations of the last century just a few metres away from the mausoleum of Caius Ennius Marsus.

\section{THE REALITY BASED 3D DIGITIZATION}

\subsection{Terrestrial photogrammetry}

In the survey of the archaeological sites, in order to allow future analysis and interpretations, it is fundamental to have a thorough and precise documentation of monuments. The photogrammetric technique is the right answer to this as it allows to acquire precise metric and radiometric data. With a digital camera and software based on ad hoc algorithms it is possible to carry out the survey of the analysed objects and to reconstruct the 3D model in a digital environment (Gonizzi Barsanti et al., 2013).

The applications of the photogrammetric survey can range from a big to a small scale: in this case we have decided to use photogrammetry both for the survey of archaeological monuments and the digital acquisition of some smaller finds that are in the Museo Provinciale Sannitico of Campobasso and in the Museo Città di Cannara (PG). In order to obtain complete metric data, some monuments were surveyed through laser scanning and the digital terrestrial photogrammetry. Merging the photogrammetric and the laser scanning data nowadays is an established methodology and it is used not only because of the thoroughness of the geometric survey, but also to improve final radiometric data. Using a digital camera and software based on algorithms of Structure from Motion (SFM) and of Dense MULTI VIEW 3D Reconstruction (DMVR) it is possible to estimate the parameters of the internal and external orientation of the photograms and thus re-create the $3 \mathrm{D}$ model of the surveyed object (Balletti et al., 2014). The SFM software used during the Summer School of Surveying and 3D Modeling and for the subsequent data elaborations, were mainly Agosoft Photoscan and 3DF Zephir Pro.

For the acquisition of the photograms of monuments we have used the digital camera Canon EOS 5D Mark with a focal length of $16 \mathrm{~mm}$. The camera has a CMOS Full Frame sensor of $36 \times 24 \mathrm{~mm}$ with a maximum resolution of 5616x3744 pixel. The images, in this case, have been acquired with a resolution resampled to $2000 \times 3000$ pixel that has permitted to obtain not too heavy photograms (file-dimension wise), nonetheless maintaining a good quality for the texture of the model.

Due to the geometrical complexity of the analysed objects, in order to cover the entire surface, it was necessary to acquire a high number of images: the Mausoleum of Caius Ennius Marsus with 27 photo (Fig. 3) and of Publius Numisius Ligus (48 photo), the Porta Benevento (71 photo) and Boiano (125 photo) have been acquired with the photogrammetry. Images have been elaborated using one of the main commercial software of Structure from Motion: Agisoft Photoscan.
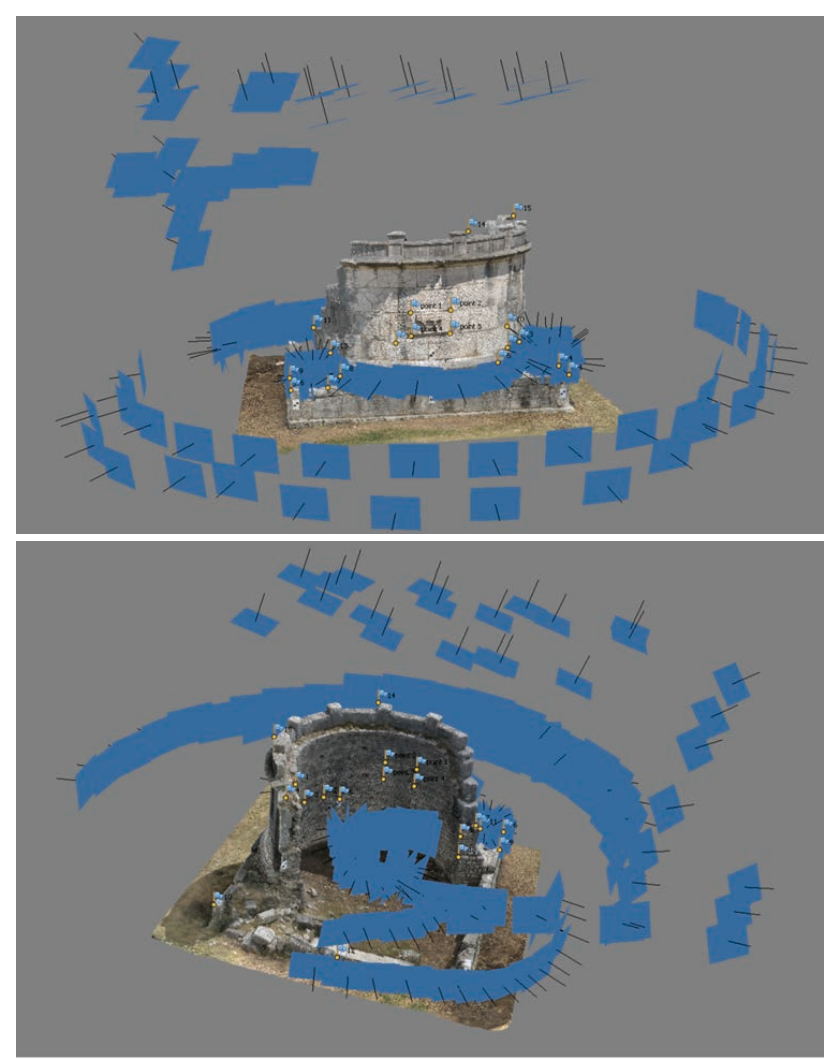

Figure 3. Photogrammetric model of C. E. Marsus's mausoleum.

Through an algorithm that matches the same points in the images, it is possible to trace the position of the camera and the geometry of the scene; in this way it is possible to visualize a sparse cloud, composed of all the points used in the matching phase. Right afterwards, the dense cloud and the triangle mesh have been created thus obtaining the 3D models of the two gates and of the mausoleum. For the phase of absolute orientation, i.e. to georeference the models in the reference system of the survey of the entire archaeological site, we have identified some points on each of the four monuments to which we have associated the coordinates obtained through topography.

After having processed the photograms, the precision of the oriented final models was less than one centimetre, therefore they were adequate for a detailed architectural representation.

The first results obtained through the applied procedures have been on one side the creation of orthophotos - extremely important for the bi-dimensional redesign - and on the other the creation of a 3D polygonal mesh, useful for rebuilding the whole archaeological site in its three dimensions in a virtual environment.

The photogrammetry technique has been used also to analyse in depth some smaller findings. In this case, we have used a digital camera Nikon D5100 with a sensor CMOS 23.6x15.7mm and a maximum resolution of $4928 \times 3264$ pixel. For the acquisitions we have used a focal length of $18 \mathrm{~mm}$. Given the geometry of the objects, it has been used a scheme of radial photo with convergent optical axes. Moreover, in order not to have areas of shadow in the final model, the images have been acquired at three different heights, covering the whole surface object of the analysis.

In this case, the objects of the survey were some findings from the site of the sanctuary of San Pietro di Cantoni of Sepino, mainly of terracotta and bronze. In particular, the survey was 
carried out on two small votive bronzes of goddesses, a thymiaterion, a male head of terracotta, a bronze flabellum handle and a bronze jug with a high handle (Fig. 4), some tanagrines and a two-faced herms made of Luni marble. In this case the images have been processed with Agisoft Photoscan, with the only difference that, since it was not possible to acquire the coordinates of certain points topographically, the objects have been scaled on a measured distance.
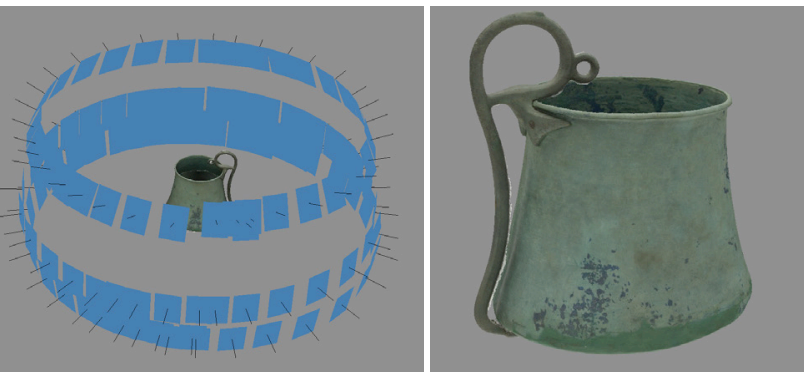

Figure 4. Photogrammetric model of a bronze jug.

The 3D models that resulted from this could be particularly useful for a virtual museum as they would allow a single visitor to interact independently with the exhibited objects. Thanks to the digital fruition of data, it will be possible to reposition in the original place the most important findings, read the historical information and analyse their shape and plasticity in the three dimensions.

The introduction of multimedia contents in a museum allows the user to interact autonomously with the information given, according to his interests and needs. The three-dimensional graphic and the virtual reality have increased the perceptive universe of fruition of information and has created new ways of approach and interaction with the contents. The need of thinking about new solutions for the communication in the museum goes together with the development of recent methodological and technological tools, whereas digital technologies can, in many cases, give answers appropriate to the needs of the museums to adapt to the changes of the society and of the communication methods. The virtual fruition of the archaeological data, widely debated in the academic world, has an increasingly important role in the establishment and encoding of communication processes that facilitate the scientific divulgation and in the planning of tools aiming at a more effective, intuitive and captivating communication of information. The creation of reproductions and maquette could allow the trial of alternative ways of divulgation, prerogative of a non-specialized public or of specific groups of visitors with certain handicaps. An alternative to the traditional plaster casts is the prototyping and the solid printing, that allow to produce very accurate copies and reproductions of the selected models, without the need of creating a direct contact with the source, thus avoiding the chances of damaging very delicate and fragile surfaces. The possibility of integration between the traditional museums and the digital tools available at very competitive prices thanks to the technological development can become a way to improve the cognitive processes and the scientific divulgation - which is actually the final aim of each research project.

\subsection{UAV photogrammetry}

In the site of Saepinum various tests have been carried out on the monuments, following different work-flows. The data obtained have been confronted with those acquired through the more traditional system for the aerial close range photogrammetry (cameras calibrated on professional drones) and/or laser scanners.
In the past few years, the development of photogrammetry with drone has developed the applications in the close range, managing to combine the aerial photogrammetric survey with the terrestrial one, introducing new low-cost possibilities compared to the traditional aerial technique. The development of software solutions for the extraction of point-clouds from groups of non-oriented images resulted in a great level of attention from the geomatic scientific community and also from external users, such as archaeologists. In the surveying campaign we have adopted two devices for the aerialphotogrammetric acquisition (Fig. 5): two professional UAV (traditional type), created by the company Neutech s.r.l, with calibrated cameras and two experimental Parrot Ar. Drone drones, normally used for recreational purposes, that are less expensive and easy to use through applications on tablets and smartphones. On the Parrots we have installed a Go Pro Hero3 Black Edition camera (Ballarin, 2014).
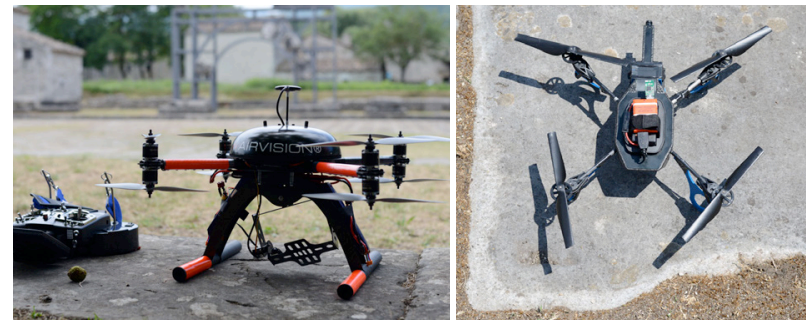

Figure 5. The two different UAV's systems used.

The first professional drone used is a hexacopter with a flight autonomy of 10-12 minutes, which can obviously vary according to the wind and the weight of the load lifted ( $\max 250$ -300 gr). The UAV uses a GPS sensor with a planar array and other integrated sensors (a triaxial accelerometer MEMS, three MEMS gyroscopes and a triaxial magnetic sensor and a pressure sensor at 12 bits) to determine the position and the balance. The system allows to register the telemetric data on a micro SD on the drone and also to transmit to the ground-station the speed of flight, the altitude, the distance from the pilot, the GPS position and above all the battery level. Moreover, it is possible to transmit in real time to the ground-station what the camera focuses, in order to facilitate the operator both in the navigation and during the manual acquisition of the photograms. The second drone is a quadricopter with eight rotors, counter-posed two by two and characterised, like in the previous model, by GPS and other integrated sensors. The recording of the flight data is carried out in the same way as for the hexacopter.

On both drones, a Canon Powershot S100 was installed, a compact and light camera (198 gr) with a good resolution (12Mpx). The camera has CMOS $1 / 17^{\prime}$ ' sensor, with dimensions of $7.44 \times 5.58 \mathrm{~mm}$, pixel of $1.86 \mathrm{~m}$. The $5 \times$ zoom allows to obtain an equivalent focal length that varies in a range between 24 and $120 \mathrm{~mm}$.

As far as the low-cost system is concerned, Parrot + Go Pro, the action cameras are more widespread and have been used more and more during extreme activities. Their photogrammetric use though has not been easy since they could not supply high resolution images and videos and additionally their geometry is far away from the theoretical model of central projection due to their wide angle or fish eye lenses. Several approaches have recently tested the use of the GoPro Hero 3 camera, particularly for the recording and/or photogrammetric use (Balletti et al., 2014).

The methodology of acquisition with UAV photogrammetry has been applied to all the archaeological sites analyzed, with the 
exception of the church of San Martino of Terravecchia, due to adverse environmental conditions.

The schemes of photos adopted in all the study cases envisage the acquisition of sequences of photogrammetric strips characterized by two different structures of view, nadiral and inclined. The choice of this last method is due to the necessity of obtaining the correct correspondence with the data acquired on the ground both with the laser scanner and the photogrammetry. In this way, integrating the different surveying methods, it is possible to obtain complete and accurate metric data, reducing the possible presence of shadows.

For each monument, we have done different flight sessions in order to obtain a redundant number of images: while for the terrestrial photogrammetry we carried out a real planning of the photos using the classical photogrammetric schemes. In the instance of the UAV photogrammetry, we have used the photo's schemes that were more appropriate for the shape of the buildings. As a consequence, in the phase of data processing, we selected the photograms useful for the creation of the different elaborations.

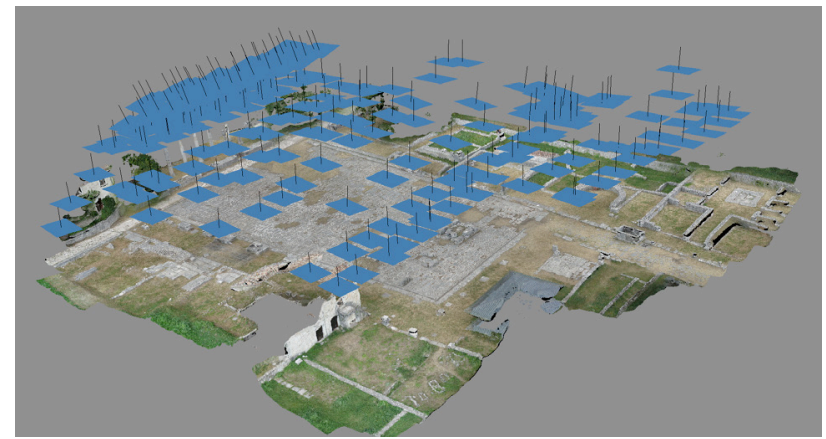

Figure 6. Photogrammetric model of Saepinum's Forum.

The choice of the method to use to set up the single structures was influenced each time by their configuration and the conservation status. Whilst for plain structures, such as the forensic area (Fig. 6) and the main road axes, the aerial photogrammetry was preferred to the laser scanning acquisitions on the ground, for more articulated buildings with high surfaces, as for example Porta Boiano (Fig. 7), it was fundamental to use different techniques together to obtain a complete survey. The final photogrammetric model, which resulted from the integration of aerial and terrestrial data, has a precision on Ground Control Points between $4 \mathrm{~mm}$ and $6 \mathrm{~mm}$, according to the elaborations.

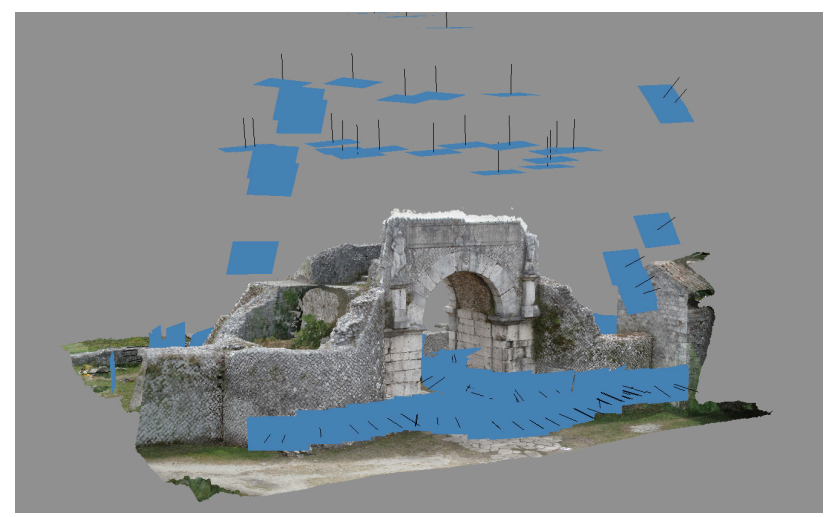

Figure 7. Photogrammetric model of Saepinum's Porta Boiano.

\subsection{Laser scanning survey}

In the field of archaeology, or generally in $\mathrm{CH}$, laser scanners (triangulation or time-of-flight) and structured-light systems were very successful, making easier the acquisition process of data related to the geometry and shape of both simple and more complex structures (Balletti et al. 2014; Tucci et al. 2013; Bonfanti et al. 2013).

Generally, active sensors can provide directly and in very short time a huge amount of $3 \mathrm{D}$ data that are normally returned as a dense point cloud to which can also be added the radiometric value for each single point.

In the sites of Molise, two laser scanners Faro Focus 3D phase shift (www.faro.com) were used as they are particularly suitable for fast acquisitions (up to 976,000 points per second) and they have a very high precision $( \pm 2 \mathrm{~mm}$ in a range between 0.6 and $120 \mathrm{~m})$.

The scans were acquired with an angular pitch of $0.035^{\circ}$, in order to guarantee the acquisition of a point every $6 \mathrm{~mm}$ at $10 \mathrm{~m}$ of distance, that is to say with a final density appropriate for the ratio 1:50. Thanks to the sensor integrated to the system, it has been possible to acquire the geometry of the structures and also the respective radiometric values.

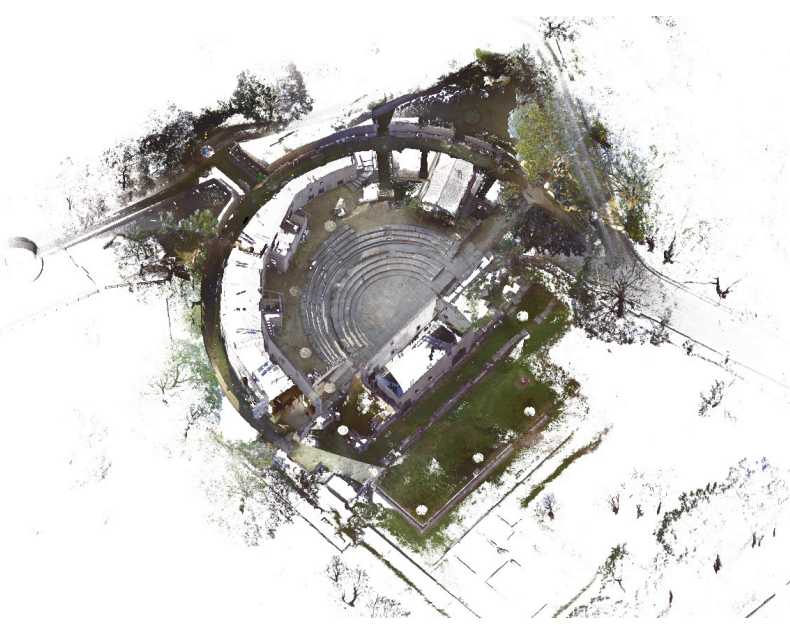

Figure 8. Point clouds of the Saepinum's theatre

The acquisition of data with laser scanner has been carried out for all the monuments described in the previous sessions. The complexity of the structures required a high number of scans, for example with the Theatre of Saepinum (Fig. 8), we carried out 45 scans in total, each one characterized by approximately 24 million points. The high number of scans is due to the high geometrical complexity of the building of which all the elements have been surveyed, including the external ambulatory.

To orientate the scans, we have used the chequered targets, whose coordinates have been acquired topographically. The only exception concerned the targets on the ambulatory walls. In this case the scans have been orientated using the method known as "cloud on cloud": only the two targets located the two opposite sides of the ambulatory have then been linked to the general net through topographic collimation. In this specific case the average precision on the alignment of the scans was of $\pm 4 \mathrm{~mm}$.

\subsection{Topographic survey}

Due to the "scattering" typical of the location of the analysed sites in the area of Sepino and of the single monuments and architectures of the city of Saepinum, it was necessary to create a topographic network that allowed to georeference the different surveys, obtained through total station and GPS. The aim was to define a homogenous reference system where it is possible to 
orientate the acquired data in relation to each surveyed structure.

To georeference the single monuments of the archaeological site of Sepino, we created a local reference system with GPS in RTK mode, using a GPS system Topcon Hiper Pro (Fig. 9). The master station was positioned on a cornerstone on top of one of the main gates of the city (Porta Boiano), while the rover was used to determine the natural target points for the photogrammetric support.

The laser scans were orientated with a topographic support made with the total station Leica TCR 1103 (Fig. 9) and afterwards they were roto-traslated in the local system of coordinates identified with the RTK survey.

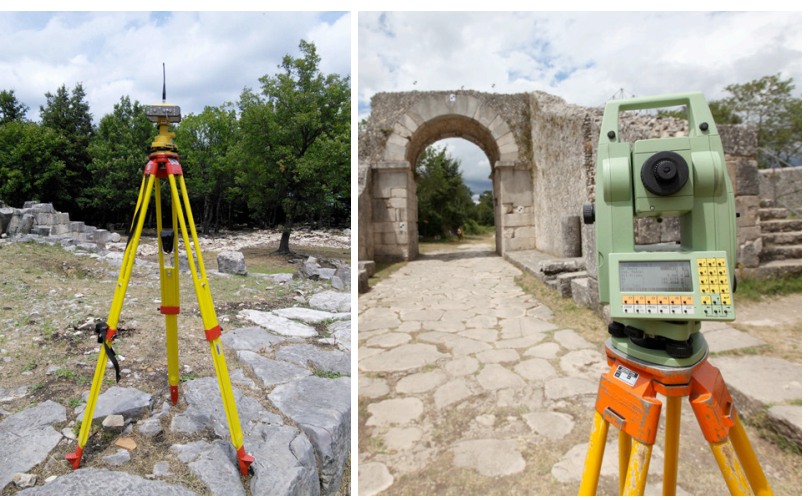

Figure 9. The topographic instruments used.

For the orientation of the photogrammetric models, such as the one of the forum, realized with the experimental low-cost system, we have identified natural points on the angles of the floor plates of the forensic area, surveyed with GPS. For the forum, contrarily to what was done for other monuments, we wanted to test the accuracies also in the borderline case where the geometry of the object is extremely difficult to reconstruct and the Ground Control Points are not easy to collimate.

\section{RESTITUTION AND RECONSTRUCTION HYPOTHESIS}

The reconstruction of the historical landscape and of urban contexts is an open question both in the strictly archaeological field and also in Virtual Archaeology; thanks to the computer graphics' potentialities the virtual systems offer an easier comprehension of contexts usually difficult to understand (Guidi et al., 2013; Kontogianni et al., 2013).

The contribution offered by GIS systems and by procedural modelling software was really useful especially due to the past researches focused on Bologna, Pompeii and Rome (De Luca et al., 2013; Müller et al., 2009; Dylla et al., 2009). In fact, the GIS systems allow an integrated and functional management of information in the same environment, whereas the procedural modelling software allows in part to automate the modelling process thanks to the application of fitting algorithms.

For this reason we decided to start a similar project on the ancient city of Saepinum, starting from the data acquired from the laser scanning and photogrammetric survey and also from the available archaeological documentation. This new research is based on a scientifically accurate and philologically virtual reconstruction of the entire urban complex. For this first part of the project, we decided not to describe the city's development from a diachronic point of view but to focus the research on a specific historical phase: the Augustan age. The archaeological investigations carried out in different areas have demonstrated the construction and the restoration of the most important buildings of the ancient city, such as the forensic area, the basilica, the thermal bath, the macellum, the sewer, the theatre with the complex of campus piscina porticus in the background and the city walls; in this particular case the documents have shown a direct intervention of the two princes of the imperial dynasty, Tiberius and Drusus (CIL, IX, 2443), between the 2 b.C. and 4 a.D. century.

We decided to use the procedural modelling software Esri's CityEngine $^{\circledR}$ for the project's realization; this work will also be supported by GIS systems (Esri $\operatorname{ArcGis}^{(B)}$ ) for the integrated management of geographical and archaeological data and also by $3 \mathrm{D}$ solid modelling software ( $3 \mathrm{dsMax}^{\circledR} \mathrm{di}$ Autodesk) for the modelling, rendering and animation phases.

The test on CityEngine ${ }^{\circledR}$, specifically created for the reconstruction of urban complexes, allows us to take advantage of the procedural modelling prerogatives. In fact, it will be possible to generate different architectonic models in an almost automatic way; the operator can set up and edit the procedural rules depending on the characteristics of urban areas.

Due to the co-operation of multidisciplinary knowledge, the reconstruction of the entire ancient city will be possible only thanks to the data elaborated from the documentation acquired on-site, confirmed by some hypothesis and by some historical and archive documentation.

It was also necessary to plan different levels of detail for the reconstruction of the forma urbis and of the city's urban structure; in fact, the complexity of the city wasn't completely known from the archaeological point of view because of the extension of some urban sectors not yet examined. For example, for the surveyed structures the level of detail is extremely high.

The urban sectors with less historical documentation will mainly benefit from the contribution and potentiality of the procedural modeling. In fact, in this case, the use of automated processes and the generation of different types of buildings, thanks to the modeling procedures of the software, will be fundamental due to the lack of archaeological documentation and historical comparison.

The potentialities of CityEngine ${ }^{\circledR}$ grammar rules of CGA (computer generated architecture) is specifically based on the generation of different types of standardized buildings, that can be reproduced on a wide extension in an almost or automatic way.

\section{CONCLUSIONS}

This work aims at testing the use of digital technologies in the field of archaeological research, focusing on the definition, the testing and the development of the techniques of indirect survey for point clouds in the different contexts of application, deepening, to this end, different acquisition systems and verifying the effectiveness in isolated or integrated forms.

The systematic and experimental application of 3D survey techniques, undertaken during the campaigns held in Terravecchia, San Pietro di Cantoni and Saepinum, allowed in most circumstances a clear acceleration of the excavation and documentation operations, leaving the detailed surveys to a second stage after the operations in the field, as it generally involves a considerable amount of time. We hope to keep going in this direction and make the application and integration of photogrammetric techniques and laser scanning in archaeology a habit and not just an occasional fact, identifying the limits and enhancing its qualities and strengths.

The digital survey currently plays a central role in the documentation and understanding of the excavation contexts, especially in the light of the instrumental and methodological progress concerning the acquisition of on-site data. The deepening of different acquisition systems and the simultaneous 
testing of their effectiveness both in isolated or integrated form is at present a specific theme of research and testing at the Laboratory of Photogrammetry of the IUAV University of Venice, always being aware that the combination of different methodologies may in fact increase the representative effectiveness of the final work and may reduce or neutralize issues related to complex surveys.

The results obtained by the integrated application of laser scanning, photogrammetry and UAV's technologies, combined with more traditional and consolidated methods of documentation related to the archaeological research, can thus be expected to allow significant progress for research itself as well as result in the reduction of the time spent on acquisition of metrological data in the field and a considerable increase in precision, accuracy and adherence to the actual survey.

The broad and varied spectrum of digital tools applicable to the field of cultural heritage can therefore provide a valuable support during key moments of the archaeological investigation, which is why, from the definition of tools and chosen methods, it is essential to proceed to their direct, constant and systematic application on the excavation site, in order to test, verify and validate the actual effectiveness in each phase and of subsequent analysis, interpretation and processing of the acquired data.

\section{REFERENCES}

\section{References from Journals:}

Balletti, C., Brussa, N., Gottardi, C., Guerra, F., 2014. The documentation and reintegration of a lost past. In: ISPRS Annals of the Photogrammetry, Remote Sensing and Spatial Information Sciences, Riva del Garda, Italy, 23-25 June 2014, pp. $49-55$.

Balletti C., Guerra F., Tsioukas V., Vernier P., 2014. Calibration of Action Cameras for Photogrammetric Purposes. In: Sensors, 14, pp. 17471-17490.

Bonfanti, C., Chiabrando, F., Rinaudo, F., 2013. TLS data for 2D representation and 3D modelling. Different approches tested in the case of San Giovanni in Salluzzo (CN) Italy. In: ISPRS Annals of the Photogrammetry, Remote Sensing and Spatial Information Sciences, Strasbourg, France, II-5/W1, pp. 37-42.

Brunetaud, X., De Luca, L., Janvier-Badosa, S., Beck, K., AlMukhtar, M., 2012. Application of digital techniques in monument preservation, European Journal of Environmental and Civil Engineering, 16 (5), pp. 543-556.

Chiabrando, F., Lingua, A., Noardo, F., Spanò, A., 2014. 3D Modelling of trompe l'oeil decorated vaults using dense matching techniques. In: ISPRS Annals of the Photogrammetry, Remote Sensing and Spatial Information Sciences, Riva del Garda, Italy, 23-25 June 2014, pp. 97-104.

Cignoni P., Scopigno R., 2008. Sampled 3D models for $\mathrm{CH}$ applications: a viable and enabling new medium or just a technological exercise. ACM Journal on Computing and Cultural Heritage 1(1), Article 2.

Colonna, G., 1962. Saepinum. Ricerche di topografia sannitica e medievale. In: Archeologia Classica, XV, pp. 80-107.

De Luca, D., Guidazzoli, A., Liguori, M. C., Spigarolo, M., 2013. Open Source e transmedialità. L'esperienza del Cineca nel campo del Virtual Heritage. In: Storicamente, n. 9, pp. 2-12.
Gonizzi Barsanti, S., Remondino, F., Visintini, D., 2013. 3D surveying and modeling of Archaeological sites - some critical issues. In: ISPRS Annals of the Photogrammetry, Remote Sensing and Spatial Information Sciences, Strasbourg, France, vol. II-5/W1, pp. 145-150.

Guidi G., Beraldin J.A., Atzeni C., 2004. High accuracy 3D modeling of Cultural Heritage: the digitizing of Donatello. IEEE Trans Image Process 13(3), pp. 370-380.

Guidi, G., Russo, M., and Angheleddu, D., 2013. Digital reconstruction of an archaeological site based on the integration of 3D data sources, In: ISPRS Archives of the Photogrammetry, Remote Sensing and Spatial Information Sciences, Trento, Italy, XL-5/W1, pp. 99-105.

Kontogianni, G., Georgopoulos, A., Saraga, N., Alexandraki, E., and Tsogka, K. 3D Virtual reconstruction of the middle stoa in the Athens ancient agorà, In: ISPRS Archives of the Photogrammetry, Remote Sensing and Spatial Information Sciences, Trento, Italy, XL-5/W1, pp. 125-131.

Patias, P., Sylaiou, S., Sechidis, L., Spartalis, I., Grussenmeyer, P., Meyer, E., Landes, T., Alby, E., 2006. A proposed low-cost system for 3D archaeological documentation. In: Proceedings of the 7th International Symposium on Virtual Reality, Archaeology and Cultural Heritage, Nicosia, Cyprus, pp. 145149.

Remondino, F., Rizzi, A., 2010. Reality-based 3D documentation of Natural and Cultural Heritage sites techniques, problems and examples, Applied Geomatics, Vol.2(3), pp. 85-100.

Tucci, G., Bonora, V., Guardini, N., 2013. Analyses of the factors affecting 3D models resolution - application to the recording of vaults in Sangallo's house. In: ISPRS Annals of the Photogrammetry, Remote Sensing and Spatial Information Sciences, Strasbourg, France, II-5/W1, pp. 307-312.

Scerrato, U., 1981. Ricerche di Archeologia medievale a Terravecchia di Sepino (notizia preliminare). In: Almanacco del Molise, pp. 109-122.

\section{References from Books:}

Dylla,K., Frischer, B., Mueller, P., Ulmer, A., Haegler, S., 2009. Rome Reborn 2.0: A Case Study of Virtual City Reconstruction Using Procedural Modeling Techniques. In: Frischer, B., Webb Crawford, J., Koller, D., (eds.), Making History Interactive. Computer Applications and Quantitative Methods in Archaeology (CAA), Oxford, pp. 62-66.

Matteini Chiari, M., Gaggiotti, M., De Benedittis, G., 1993. Saepinum, Campobasso.

Matteini Chiari, M., (ed.), 2004. La Dea, il Santo, una Terra. Materiali dallo scavo di San Pietro di Cantoni di Sepino. Spoleto, 2004.

Müller, P., Vereenooghe, T., Ulmer, A., Van Gool, L., 2005. Automatic reconstruction of Roman Housing Architecture. In: Recording, Modeling and Visualization of Cultural Heritage, Ascona, Switzerland. 


\section{References from Other Literature:}

Ballarin M., 2014. Fotogrammetria aerea low-cost in Archeologia. Tesi di dottorato, Corso di Dottorato in Ingegneria Ambientale e delle Infrastrutture, Dipartimento di Ingegneria Civile e Ambientale, Politecnico di Milano.

\section{References from Websites:}

English Heritage, 2011. 3D Laser Scanning for Heritage. Advice and guidance to users on laser scanning in archaeology and architecture. Available at www.english-heritage.org.uk

Faro Focus 3D, http://www.faro.com/it-it/home 